\title{
Value of systemic PET/CT in the diagnosis and differential diagnosis of aplastic anemia
}

\author{
MEILAN CHEN $^{1 *}$, LIYUAN LU $^{2 *}$, JUAN LI $^{1}$, BIN ZHANG $^{3}$, JUNRU LIU $^{1}$, JINGLI GU $^{1}$, \\ DONG ZHENG ${ }^{1}$, XIUZHEN TONG ${ }^{1}$ and HEHUA WANG ${ }^{1}$
}

\author{
${ }^{1}$ Department of Hematology, The First Affiliated Hospital, Sun Yat-Sen University, Guangzhou, Guangdong 510080; \\ ${ }^{2}$ Department of Electronic Engineering, Engineering Faculty, The Chinese University of Hong Kong, \\ Hong Kong 999077, SAR; ${ }^{3}$ Department of Nuclear Medicine, The First Affiliated Hospital, \\ Sun Yat-Sen University, Guangzhou, Guangdong 510080, P.R. China
}

Received September 28, 2016; Accepted June 6, 2018

DOI: $10.3892 / \mathrm{ol} .2018 .9049$

\begin{abstract}
The aim of the present study was to investigate the value of systemic $\left[{ }^{18} \mathrm{~F}\right]$ fluorodeoxyglucose positron emission tomography (PET)/computed tomography (CT) in the diagnosis and differential diagnosis of aplastic anemia (AA). Systemic PET/CT imaging results of 24 patients diagnosed with AA in The First Affiliated Hospital of Sun Yat-Sen University between May 2011 and August 2014 were retrospectively analyzed and compared with results from healthy individuals and patients with acute leukemia (AL) or myelodysplastic syndrome (MDS) in the same period to summarize the PET/CT characteristics of patients with AA. Systemic $\mathrm{PET} / \mathrm{CT}$ manifestations of the 24 patients with AA were classified into three types: Normal bone marrow metabolism, hypometabolism and hypometabolism complicated by focal hyperproliferation. Focal hyperproliferation was frequently identified in the vertebral body, breast bones and iliac bones. Bone marrow maximum standardized uptake values (SUV) of AA were associated, to certain extents, with the degree of proliferation and the bone marrow T/B cell ratio. The overall bone marrow SUV of AA were lower compared with those of healthy individuals and AL or patients with MDS, indicating hypometabolism. Considering the T/B cell ratio, systemic $\mathrm{PET} / \mathrm{CT}$ manifestations of patients with AA are able to predict treatment responses to certain degrees. Systemic PET/CT is highly valuable in the diagnosis and differential diagnosis of $\mathrm{AA}$, and may also indicate treatment responses.
\end{abstract}

Correspondence to: Dr Juan Li, Department of Hematology, The First Affiliated Hospital, Sun Yat-Sen University, 58 Zhongshan Second Road, Guangzhou, Guangdong 510080, P.R. China E-mail: 13719209240@163.com

*Contributed equally

Key words: aplastic anemia, systemic positron emission tomography/ computed tomography, standardized uptake value, diagnosis and differential diagnosis

\section{Introduction}

$\left[{ }^{18} \mathrm{~F}\right]$ fluorodeoxyglucose $\left(\left[{ }^{18} \mathrm{~F}\right] \mathrm{FDG}\right)$ positron emission tomography (PET)/computed tomography (CT) is a novel imaging technique that integrates functional metabolism imaging and anatomical form imaging. Imaging foci of malignant tumors is based on the increased glucose uptake of malignant tumor cells, which display morphology and sizes of foci, and, more importantly, the absence/presence and levels of activity of malignant tumor foci (1). PET/CT has been extensively used in diagnosis of malignant tumors. Aplastic anemia (AA) is a common hematological disease characterized by bone marrow hypoproliferation and is, in certain cases, difficult to differentiate from myelodysplastic syndrome (MDS). According to the working mechanism of PET/CT, it is hypothesized that this technique is potentially useful in diagnosis of AA and differential diagnosis from MDS.

To the best of our knowledge, the function of systemic $\mathrm{PET} / \mathrm{CT}$ in AA has only previously been investigated in individual cases (2-4). No literature is available that systemically introduces characteristics of PET/CT manifestations in patients with AA and its value in the clinical setting. In the present study, characteristics of systemic PET/CT of 24 patients with AA were compared with those of healthy individuals and patients with acute leukemia (AL) or MDS to investigate the value of systemic PET/CT in diagnosis and differential diagnosis of AA and reveal its functionin indicating treatment responses when the T/B cell ratio was taken into account.

\section{Patients and methods}

Study population. In total, 24 patients were included who had been diagnosed with AA and undergone systemic PET/CT examination in The First Affiliated Hospital of Sun Yat-Sen University between May 2011 and August 2014. All patients were diagnosed according to the 2009 British guidelines for the diagnosis and management of AA (5). Of these patients, 17 presented with severe aplastic anemia (SAA) and the other 7 presented with chronic aplastic anemia (CAA). The general features of the 24 patients with AA at the onset of the disease are presented in Table I. The median age at diagnosis was 38.3 years (range, $13.0-75.0$ years). 
The present study also included 16 healthy individuals, 6 patients with AL and 4 patients with MDS. Patients with AL were diagnosed according to the 2008 revision of the World Health Organization (WHO) classification of myeloid neoplasms and acute leukemia (6), and patients with MDS were diagnosed according to the 2007 version of the Vienna minimal diagnostic criteria (7) and the 2008 version of the WHO classification criteria (6). Of the 6 patients with AL, 4 presented with acute myelocytic leukemia and 2 presented with acute lymphoblastic leukemia; of the 4 patients with MDS, 1 presented with MDS-refractory anemia with excess blasts (RAEB) type I, 1 presented with MDS-RAEB type II and the other 2 presented with MDS-refractory cytopenia with multilineage dysplasia. Of the 16 healthy individuals, 11 were male and 5 were female. The present study was approved by the ethics committee of the First Affiliated Hospital of Sun Yat-sen University, and study participants provided written informed consent.

Therapeutic regimens and follow-up. Of the 7 patients with CAA, 1 discontinued treatment, and the other 6 received ciclosporin A (CsA) treatment; of the 17 patients with SAA, 5 discontinued treatment, 5 underwent allogeneic hematopoetic stem cell transplantation (allogeneic bone marrow transplantation from a human leucocyte antigen-identical sibling donor), 3 received antithymocyte globulin (ATG) sequential CsA treatment and 4 accepted only CsA treatment. The 2009 British guidelines for the diagnosis and management of AA (5) were used as the reference. The responses of patients were evaluated following treatment for 6 weeks. The response rate was the sum of complete remission (CR) rate and partial remission $(\mathrm{PR})$ rate.

Methods. Prior to examination, all patients fasted for $>6 \mathrm{~h}$. Following intravenous injection of $\left[{ }^{18} \mathrm{~F}\right] \mathrm{FDG}$, patients rested in the supine position for between 50 and $60 \mathrm{~min}$ in a quiet and warm indoor environment. Following complete evacuation of urine, with each patient lying in the supine position on the examination bed, spiral CT scanning was first performed from the roof of the skull to the upper end of the femoral bone, prior to performing systemic 2D PET section imaging. The cross-sectional image underwent attenuation correction using the CT cross-sectional image at the same layer as emission imaging; PET image reconstruction was performed by ordered subset expectation maximization iterative reconstruction method. The reconstructed image and the CT image were fused to obtain coronal, sagittal, cross-sectional CT, PET and PET/CT images, respectively. Two nuclear medicine physicians, who were blinded to the clinical disease of the patients, analyzed the patient images and, using semi-quantitative analysis, selected all parts with hypermetabolism and sketched the region of interest for the workstation to automatically generate the maximum standardized uptake values $\left(\mathrm{SUV}_{\max }\right)$.

Statistical analysis. Statistical analysis of the results was performed using the $\chi^{2}$ test, non-parametric rank sum test, Fisher's exact test, and Pearson' scorrelation coefficient using SPSS software (version 19.0; IBM Corp., Armonk, NY, USA). $\mathrm{P}<0.05$ was considered to indicate a statistically significant difference.
Table I. General characteristics of the 24 patients with AA at onset of disease.

\begin{tabular}{lc}
\hline Factors & $\mathrm{n}(\%)$ \\
\hline Male & $14(58.3)$
\end{tabular}

Disease classification

\section{CAA}

SAA

White blood cell count, cells/1

$$
\begin{aligned}
& \geq 2.0 \times 10^{9} \\
& <2.0 \times 10^{9}
\end{aligned}
$$

Neutrophil cell count, cells/1

$\geq 0.5 \times 10^{9}$

$<0.5 \times 10^{9}$

Hemoglobin, g/1

$\geq 90$

$<90$

Net woven red blood cell count, cells/1

$\geq 24 \times 10^{9}$

Platelet, cells/1

$\geq 50 \times 10^{9}$

$<50 \times 10^{9}$

Alanine aminotransferase, $\mathrm{U} / \mathrm{l}$

$\geq 40$

$<40$

Albumin, g/l

$\geq 35$

$<35$

Lactate dehydrogenase, U/1

$\geq 240$

$<240$

Serum creatinine, $\mu \mathrm{mol} / 1$

$\geq 115$

$<115$

Infection

Yes

No

$16(66.7)$

${ }^{\mathrm{a}} \mathrm{P}<0.05$ vs. AA group; ${ }^{\mathrm{b}} \mathrm{P}<0.01$ vs. AA group. AA, anaplastic anemia; CAA, chronic AA; SAA, severe AA.

\section{Results}

Characteristics of systemic PET/CT manifestations of healthy individuals. The 16 healthy individuals included 11 males and 5 females, whose median age was 50.0 years (range, 36-72 years). They underwent systemic PET/CT examination for the purpose of routine physical examination. No marked abnormality in bone marrow metabolism or abnormal $\left[{ }^{18} \mathrm{~F}\right] \mathrm{FDG}$ concentration was identified in the 16 individuals (Fig. 1A and B). 


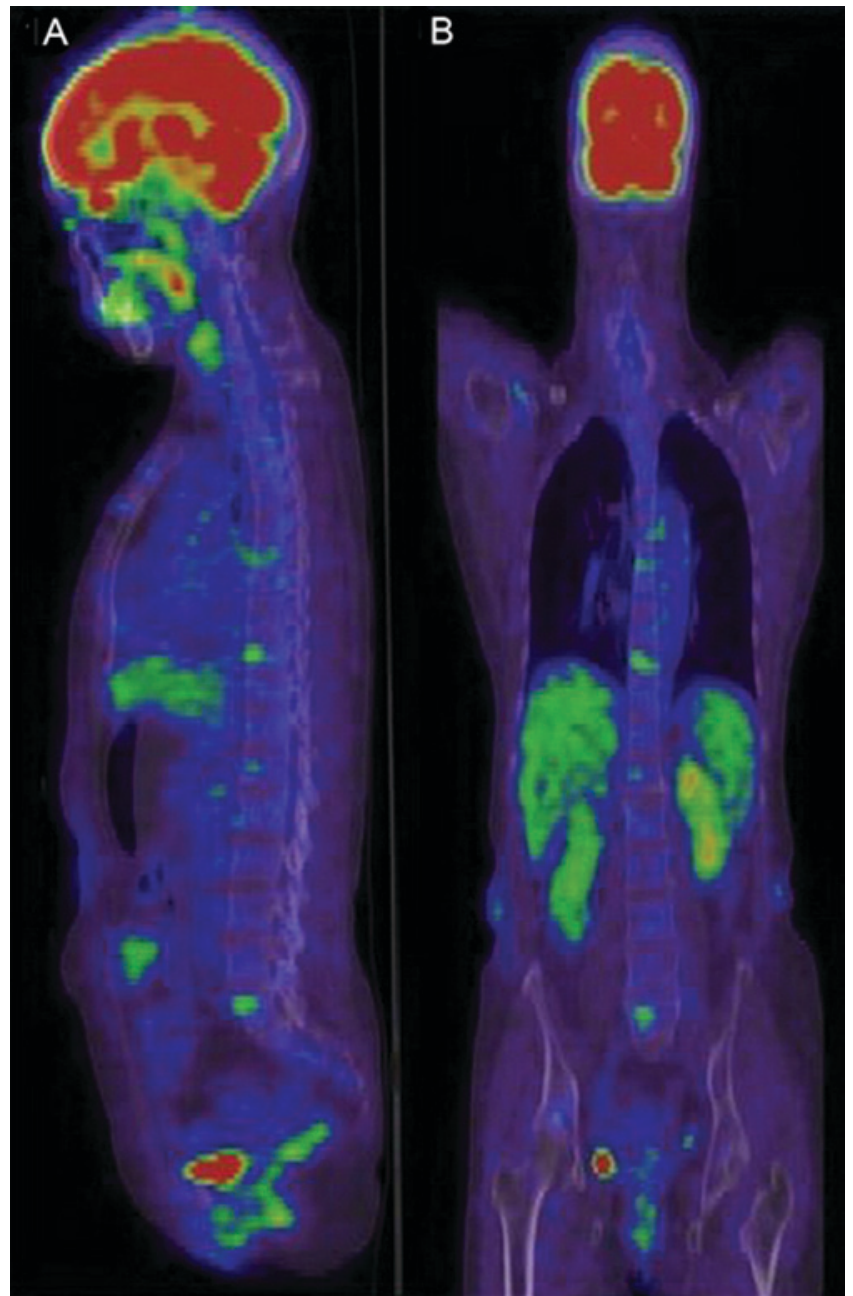

Figure 1. Positron emission tomography/computed tomography scans of healthy individuals. (A) Coronal and (B) sagittal images of healthy individuals.

Characteristics of systemic PET/CT manifestations of patients with AA

Bone marrow PET/CT manifestations of patients with AA. Bone marrow PET/CT manifestations of patients with AA were classified into the following three types (Table II): Hypometabolism complicated by focal hyperproliferation (Fig. 2A and B), hypometabolism (Fig. 2C and D) and normal bone marrow metabolism (Fig. 2E and F). Of the 24 patients with AA, 1 (4.2\%) presented with normal bone marrow metabolism, $9(37.5 \%)$ presented with hypometabolism and $14(58.3 \%)$ presented with hypometabolism complicated by focal hyperproliferation.

Differences in bone marrow PET/CT manifestations in patients with AA. Differences in the bone marrow PET/CT manifestations of patients with different types of AA were observed. Of the 17 patients with SAA, $1(5.9 \%)$ presented with normal bone marrow metabolism, 7 (41.2\%) presented with hypometabolism and $9(52.9 \%)$ presented with hypometabolism complicated by focal hyperproliferation; of the 7 patients with CAA, none presented with normal bone marrow metabolism, $2(28.6 \%)$ presented with hypometabolism and $5(71.4 \%)$ presented with hypometabolism complicated by focal hyperproliferation.
Commonality in focal proliferation in PET/CT of patients with $A A$. Of the 24 patients with AA, 14 (58.3\%) presented with diffuse hypometabolism complicated by focal hyperproliferation and increased uptake in systemic PET/CT. The SUV of parts with hyperproliferation were between 2.2 and 8.8; parts with focal hyperproliferation included (in descending order): Vertebral body $(54.2 \%)$, breast bones $(41.7 \%)$, ilial bones $(25.0 \%)$, ribs $(16.7 \%)$, upper segment of femoral bone $(16.7 \%)$, sacral bone (16.7\%), scapular bones $(12.5 \%)$, collar bones $(8.3 \%)$, ischial bones $(4.2 \%)$ and upper segments of humeral bones $(4.2 \%)$.

Association between presencelabsence of concurrent infections and PET/CT focal hyperproliferation $S U V_{\text {max }}$ in patients with $A A$. Owing to marked leukopenia and neutropenia, infections are common complications of patients with AA (5). In the present study, 8/24 patients with AA presented with concurrent infections, which affected lungs, gums and the upper respiratory tracts. In total, $3 / 8$ patients with concurrent infections presented with bone marrow hypometabolism complicated by focal hyperproliferation $\left(\mathrm{SUV}_{\max }=5.70 \pm 1.92\right)$. In total, $11 / 16$ patients without concurrent infections presented with bone marrow hypometabolism complicated by focal hyperproliferation $\left(\mathrm{SUV}_{\max }=3.10 \pm 0.28\right)$. A statistically significant difference was identified between the two groups $(\mathrm{P}=0.028)$. Only $1 / 24$ patients developed concurrent infections at onset of the disease (bone marrow $\mathrm{SUV}_{\max }=8.30$ ) and thus was first administered active anti-infective therapy. Later, the patient's infection was controlled. After 1 month, the bone marrow $\mathrm{SUV}_{\max }$ decreased to 1.70 in systemic PET/CT re-examination.

Association between bone marrow $S U V_{\max }$ and the $T / B$ cell ratio. All of the 24 patients with AA underwent bone marrow flow cytometric examination to determine the ratio between $\mathrm{T}$ lymphocytes and B lymphocytes (T/B ratio). High values of the $\mathrm{T} / \mathrm{B}$ ratio indicate abnormal activation of $\mathrm{T}$ cells. Depending on the bone marrow $\mathrm{SUV}_{\max }$, the patients were divided into two groups, one group with $\mathrm{SUV}_{\max } \geq 3.00$ and the other group with $\mathrm{SUV}_{\max }<3.00$. T/B ratios of the two groups were calculated. The T/B cell ratios of the group with $\mathrm{SUV}_{\max } \geq 3.00$ and the group with $\mathrm{SUV}_{\max }<3.00$ were 3.37 (2.49-6.39) and 8.74 (7.22-13.96), respectively; the difference between the two groups was statistically significant $(\mathrm{P}=0.014)$.

Association between the degree of bone marrow proliferation and $\left[{ }^{18} F\right] F D G$ uptake activity in PET/CT. Each of the 24 patients with AA underwent iliac bone marrow smear examination at least twice, ilial bone biopsy once and sternal bone marrow smear examination once. It was identified that the PET/CT metabolic activity was positively correlated with the degree of proliferation at this part (including ilial bones and breast bones) $(\mathrm{P}<0.001)$, with Pearson's correlation coefficient, R, of 0.572 . Therefore, metabolic activity shown in PET/CT may indicate, to a certain extent, the degree of bone marrow proliferation.

Characteristics of systemic PET/CT manifestations of patients with $A L$ and MDS

Characteristics of systemic PET/CT manifestations of patients with $A L$. The 6 patients with AL included 4 males and 2 
Table II. Characteristics of bone marrow PET/CT manifestations of patients with different types of AA.

\begin{tabular}{lllr}
\hline Bone marrow manifestation in PET/CT & SAA, n (\%) & CAA, n (\%) & Total, n (\%) \\
\hline Normal metabolism & $1 / 17(5.9)$ & $0 / 7(0)$ & $1 / 24(4.2)$ \\
Hypometabolism & $7 / 17(41.2)$ & $2 / 7(28.6)$ & $9 / 24(37.5)$ \\
Hypometabolism complicated by focal hyperproliferation & $9 / 17(52.9)$ & $5 / 7(71.4)$ & $14 / 24(58.3)$ \\
\hline
\end{tabular}

PET, positron emission tomography; CT, computed tomography; AA, aplastic anemia; SAA, severe AA; CAA, chronic AA.

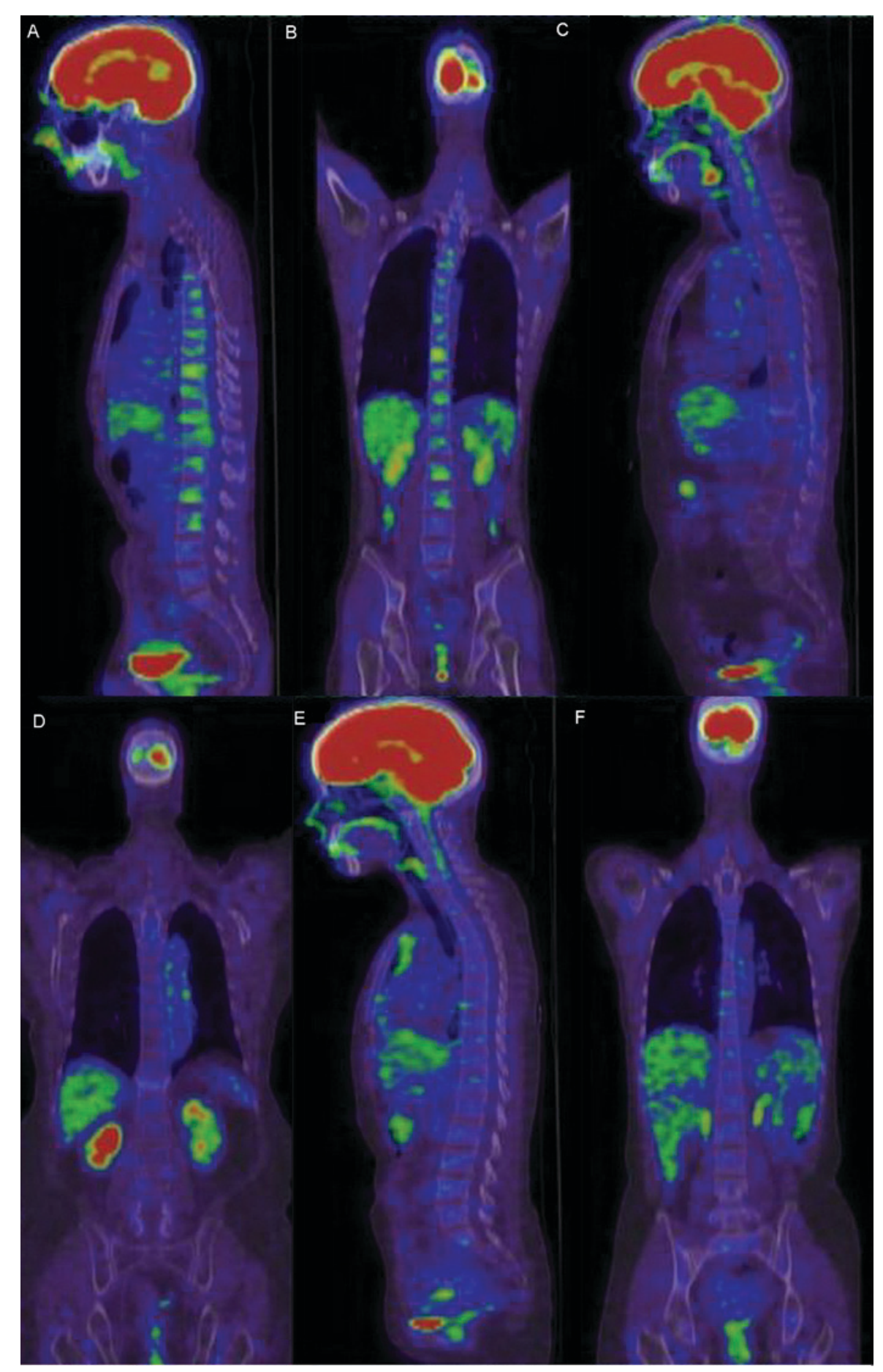

Figure 2. PET/CT scans of patients with AA. (A) Coronal and (B) sagittal images of patients with AA with diffuse hypometabolism complicated by focal hypermetabolism and increased uptake in systemic PET/CT. (C) Coronal and (D) sagittal images of patients with AA with generalized bone marrow hypometabolism in systemic PET/CT. (E) Coronal and (F) sagittal images of patients with AA with normal metabolism. PET, positron emission tomography; CT, computed tomography; AA, aplastic anemia. 


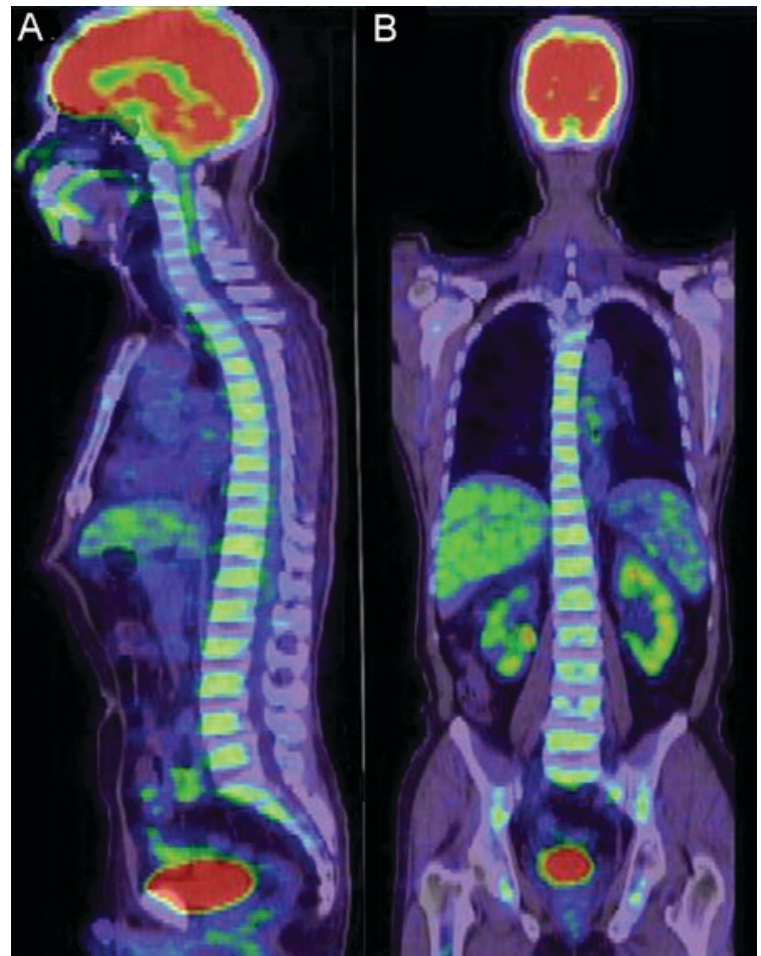

Figure 3. Positron emission tomography/computed tomography scans of patients with AL. (A) Coronal and (B) sagittal images of patients with AL. AL, acute leukemia.

females, whose median age was 53 years (range, 18-75 years). Systemic PET/CT of all 6 patients revealed diffuse hypermetabolism in the axial skeleton and limb bones (Fig. 3), and the $\mathrm{SUV}_{\max }$ were between 2.50 and 5.60. In total, 2 patients presented with spleen enlargement and active metabolism, and the spleen $\mathrm{SUV}_{\max }$ were 2.30 and 3.60, respectively.

Characteristics of systemic PET/CT manifestations of patients with MDS. The 4 patients with MDS included 2 males and 2 females, whose median age was 58.7 years (49-69 years). In total, 1 patient presented with generalized hypometabolism complicated by focal hypermetabolism (breast bones) (Fig. 4A and B); 3/4 patients presented with diffuse and uniform hypermetabolism in the axial skeleton and limb bones (Fig. 4C and D), and the $\mathrm{SUV}_{\max }$ were between 2.60 and 8.50. In total, 1/4 patients with MDS presented with mild spleen enlargement; spleens of the other 3 patients were the normal size.

Comparison of overall bone marrow and extramedullar SUV of patients with AA and healthy individuals or patients with AL or MDS. As presented in Table III, the differences between bone marrow SUV of patients with AA and healthy individuals or patients with AL or MDS were all statistically significant $(\mathrm{P}<0.01)$, indicating that the overall bone marrow metabolism of patients with AA was low. Spleen SUV of patients with MDS and patients with AL were higher compared with those of patients with AA, and the differences were statistically significant $(\mathrm{P}=0.020$ and 0.026 , respectively). No statistically significant difference was identified in liver and mediastinal blood pool SUV between patients with AA and healthy individuals, patients with $\mathrm{AL}$ or patients with $\operatorname{MDS}(\mathrm{P}>0.05)$.

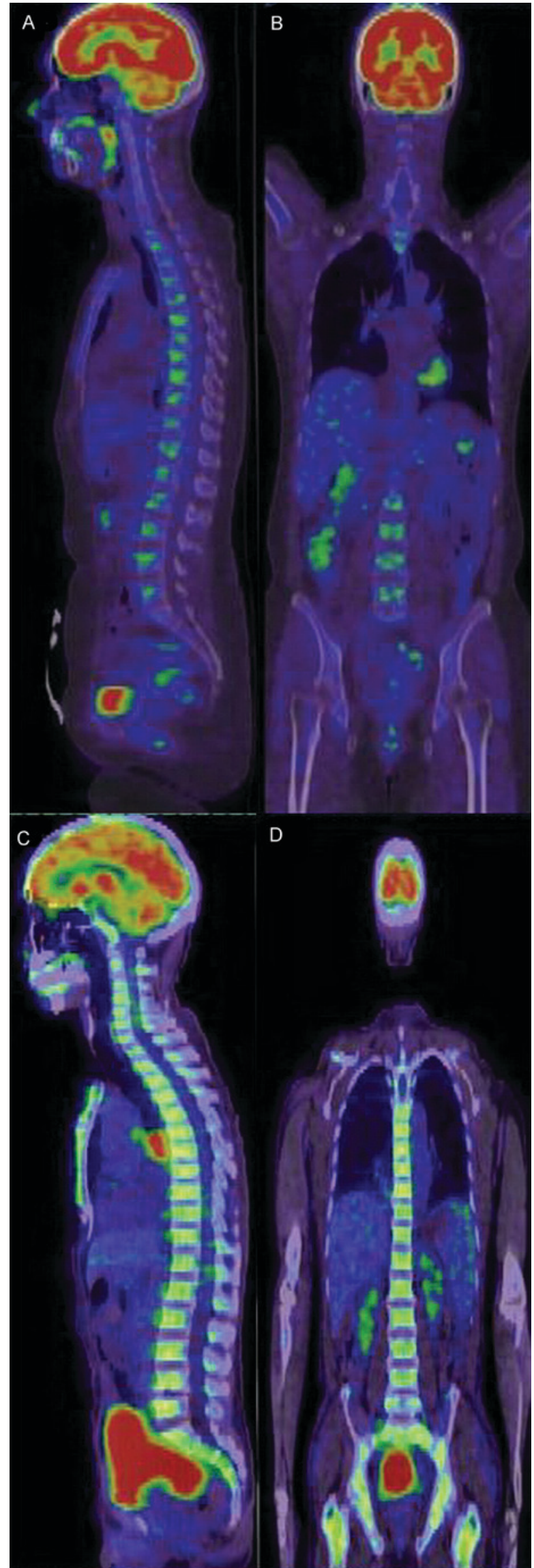

Figure 4. Positron emission tomography/computed tomography scans of patients with MDS. (A) Coronal and (B) sagittal images of diffuse hypometabolism complicated by focal hyperproliferation in patients with MDS. (C) Coronal and (D) sagittal images of diffuse and uniform hypermetabolism. MDS, myelodysplastic syndrome. 
Table III. Comparison of standardized uptake values of different parts of patients with AA and healthy individuals, patients with AL and patients with MDS.

\begin{tabular}{lcccc}
\hline Disease type & $\begin{array}{c}\text { Bone marrow } \\
\text { (median, quartile) }\end{array}$ & $\begin{array}{c}\text { Liver } \\
\text { (median, quartile) }\end{array}$ & $\begin{array}{c}\text { Spleen } \\
\text { (median, quartile) }\end{array}$ & $\begin{array}{c}\text { Mediastinum } \\
\text { (median, quartile) }\end{array}$ \\
\hline AA & $0.90(0.65-1.30)$ & $2.00(1.78-2.06)$ & $1.80(1.63-2.15)$ & $1.30(1.24-1.49)$ \\
Healthy & $1.65(1.36-1.80)^{\mathrm{b}}$ & $2.00(1.84-2.40)$ & $1.68(1.50-2.00)$ & $1.30(1.20-1.56)$ \\
MDS & $2.75(2.43-5.65)^{\mathrm{b}}$ & $1.90(1.30-2.50)$ & $2.10(2.00-3.10)^{\mathrm{a}}$ & $1.25(0.85-1.65)$ \\
AL & $3.09(2.68-3.55)^{\mathrm{b}}$ & $2.15(1.84-2.53)$ & $2.11(1.93-2.63)^{\mathrm{a}}$ & $1.52(1.15-1.70)$ \\
\hline
\end{tabular}

AA, aplastic anemia; MDS, myelodysplastic syndrome; AL, acute leukemia. ${ }^{\mathrm{a}} \mathrm{P}<0.05$ vs. AA group; ${ }^{\mathrm{b}} \mathrm{P}<0.01$ vs. AA group.

Table IV. PET/CT manifestations, T/B cell ratios and treatment responses of 18 treated patients with AA.

\begin{tabular}{|c|c|c|c|c|c|c|c|c|}
\hline No. & Sex & $\begin{array}{l}\text { Age, } \\
\text { years }\end{array}$ & Diagnosis & PET/CT manifestation & $\mathrm{SUV}_{\max }$ & $\begin{array}{c}\mathrm{T} / \mathrm{B} \\
\text { cell ratio }\end{array}$ & $\begin{array}{l}\text { Therapeutic } \\
\text { regimen }\end{array}$ & Efficacy \\
\hline 1 & Male & 24 & CAA & $\begin{array}{l}\text { Hypometabolism complicated } \\
\text { by focal hyperproliferation }\end{array}$ & 6.10 & 5.62 & $\mathrm{CsA}$ & $\mathrm{CR}$ \\
\hline 2 & Male & 50 & CAA & $\begin{array}{l}\text { Hypometabolism complicated } \\
\text { by focal hyperproliferation }\end{array}$ & 8.80 & 13.86 & CsA & PR \\
\hline 3 & Female & 59 & CAA & Diffuse hypometabolism & 1.80 & 16.85 & CsA & PR \\
\hline 4 & Female & 60 & CAA & $\begin{array}{l}\text { Hypometabolism complicated } \\
\text { by focal hyperproliferation }\end{array}$ & 2.90 & 2.22 & CsA & $\mathrm{NC}$ \\
\hline 5 & Male & 23 & CAA & $\begin{array}{l}\text { Hypometabolism complicated } \\
\text { by focal hyperproliferation }\end{array}$ & 3.20 & 8.74 & CsA & PR \\
\hline 6 & Female & 54 & CAA & $\begin{array}{l}\text { Hypometabolism complicated } \\
\text { by focal hyperproliferation }\end{array}$ & 2.20 & 7.61 & CsA & PR \\
\hline 7 & Female & 34 & SAA & Normal metabolism & 2.00 & 3.02 & ATG & PR \\
\hline 8 & Male & 14 & SAA & $\begin{array}{l}\text { Hypometabolism complicated } \\
\text { by focal hyperproliferation }\end{array}$ & 2.50 & 2.53 & ATG & PR \\
\hline 9 & Male & 27 & SAA & $\begin{array}{l}\text { Hypometabolism complicated } \\
\text { by focal hyperproliferation }\end{array}$ & 2.70 & 5.62 & ATG & $\mathrm{CR}$ \\
\hline 10 & Female & 75 & SAA & Diffuse hypometabolism & 1.10 & 3.07 & CsA & $\mathrm{CR}$ \\
\hline 11 & Female & 26 & SAA & $\begin{array}{l}\text { Hypometabolism complicated } \\
\text { by focal hyperproliferation }\end{array}$ & 3.10 & 8.99 & CsA & $\mathrm{NC}$ \\
\hline 12 & Male & 36 & SAA & $\begin{array}{l}\text { Hypometabolism complicated } \\
\text { by focal hyperproliferation }\end{array}$ & 5.00 & 5.86 & CsA & $\mathrm{NC}$ \\
\hline 13 & Male & 48 & SAA & Diffuse hypometabolism & 1.50 & 5.28 & CsA & PR \\
\hline 14 & Male & 13 & SAA & Diffuse hypometabolism & 1.3 & 10.51 & Allo-BMT & $\mathrm{CR}$ \\
\hline 15 & Female & 43 & SAA & $\begin{array}{l}\text { Hypometabolism complicated } \\
\text { by focal hyperproliferation }\end{array}$ & 4.5 & 7.43 & Compatriots & $\mathrm{CR}$ \\
\hline 16 & Male & 43 & SAA & $\begin{array}{l}\text { Hypometabolism complicated } \\
\text { by focal hyperproliferation }\end{array}$ & 2.8 & 3.66 & Compatriots & $\mathrm{CR}$ \\
\hline 17 & Male & 43 & SAA & $\begin{array}{l}\text { Hypometabolism complicated } \\
\text { by focal hyperproliferation }\end{array}$ & 3.0 & 7.22 & Compatriots & $\mathrm{CR}$ \\
\hline 18 & Male & 37 & SAA & $\begin{array}{l}\text { Hypometabolism complicated } \\
\text { by focal hyperproliferation }\end{array}$ & 3.0 & 16.75 & Compatriots & $\mathrm{CR}$ \\
\hline
\end{tabular}

CAA, chronic aplastic anemia; SAA, severe aplastic anemia; PET/CT, positron emission tomography/computed tomography; $\mathrm{SUV}_{\max }$, maximum standardized uptake values; T/B cell ratio, ratio between T lymphocytes and B lymphocytes; CsA, ciclosporin A; Allo-BMT, allogeneic bone marrow transplantation from a human leucocyte antigen-identical sibling donor; CR, complete remission; PR, partial remission; NC, no change.

AA association between patient treatment responses and $P E T / C T$. Of the 24 patients with AA, 6 discontinued treatment.
Treatment responses of the other 18 patients are presented in Table IV. Of the 6 patients with CAA treated with CsA, 
5 responded and the other did not. Bone marrow of the non-responder presented with hypometabolism was complicated by focal hyperproliferation, the $\mathrm{SUV}_{\max }$ was 2.90 , and the T/B cell ratio was 2.22 . Of the 4 patients with SAA treated with CsA, 2 responded and the other 2 did not. $\mathrm{SUV}_{\max }$ of both respondents were not high, and the $\mathrm{T} / \mathrm{B}$ cell ratios were also lower compared with those of the 2 non-respondents; of the 2 non-respondents, $\mathrm{SUV}_{\max }$ were high, and the T/B cell ratios were also significantly higher. All 3 patients treated with ATG responded.

\section{Discussion}

The results of present study have suggested that systemic PET/CT of patients with AA has specific manifestations, and may assist in differentiating from atypical MDS and, with the $\mathrm{T} / \mathrm{B}$ cell ratio taken into account, may predict treatment responses.

Systemic PET/CT has been increasingly used in diagnosis and treatment of tumor patients. $\left[{ }^{18} \mathrm{~F}\right] \mathrm{FDG}$ is a glucose analog identical with glucose in terms of the approach and method of entering cells. The quantity of glucose transporters on the surface of tumor cells has increased, so the glucose metabolic rate of tumor cells is high. However, $\left[{ }^{18} \mathrm{~F}\right] \mathrm{FDG}$ is not a tumor-specific tracer. In certain benign lesions, infections, inflammatory reactions or diseased parts with markedly active proliferation, glucose uptake and metabolism are also enhanced $(8,9)$, manifesting as increased $\mathrm{SUV}_{\max }$ in PET/CT.

The results of the present study indicate that systemic PET/CT manifestations of patients with AA may be classified into three types: Hypometabolism complicated by focal hyperproliferation, hypometabolism and normal bone marrow metabolism. In SAA or CAA, the most common systemic $\mathrm{PET} / \mathrm{CT}$ manifestation is hypometabolism complicated by focal hyperproliferation, followed by hypometabolism, and the most common parts with focal hypermetabolism are the vertebral body, chest bones and ilial bones. Cicone et al (2) reported focal hypermetabolism in $\mathrm{PET} / \mathrm{CT}$ of a patient with AA, whose $\mathrm{SUV}_{\max }$ was 2.80 and in whom focal hypermetabolism was primarily identified in the vertebral body, and these results were essentially consistent with those of the present study. The results of the present study also indicated that the metabolic activity identified using PET/CT is positively correlated with the degree of bone marrow proliferation at the corresponding part. According to the working mechanism of PET/CT, it is considered that the increase in $\mathrm{SUV}_{\max }$ is associated with active focal bone marrow-compensated proliferation and increased glucose uptake in bone marrow cells, so metabolic activity shown in PET/CT may indicate, to a certain extent, the degree of bone marrow proliferation (10-12). Additionally, systemic PET/CT may reveal the metabolic activity of bone marrow of the whole body and thus may more comprehensively reflect the situation of bone marrow proliferation compared with bone marrow aspiration or biopsy of individual parts.

Infections are common complications of patients with AA (5). SUV $\mathrm{max}_{\text {max }}$ of parts with focal hypermetabolism of patients with AA with concurrent infections were higher compared with those of patients with AA without infections, indicating that infection is another factor that influences $\mathrm{SUV}_{\max }$.
According to previously published studies, the pathogenesis of AA involves inherent defects in hematopoietic stem cells, supportive function defects of hematopoietic microenvironments and immune function disorders; in particular, abnormal T lymphocyte immunity serves an important function in development and progression of AA (13). Peripheral blood and bone marrow $\mathrm{T}$ lymphocytes of patients are abnormally activated, producing soluble cytokines to inhibit hematopoiesis. In the present study, the association between the $\mathrm{T} / \mathrm{B}$ cell ratio and the $\mathrm{SUV}_{\max }$ of bone marrow has been preliminarily investigated. The results indicate that bone marrow $\mathrm{SUV}_{\max }$ of patients with high $\mathrm{T} / \mathrm{B}$ cell ratios are also high; an abnormal increase in the $\mathrm{T} / \mathrm{B}$ cell ratio reflects, to a certain extent, abnormal activation of T cells. Therefore, bone marrow $\mathrm{SUV}_{\text {max }}$ of patients with AA indicate compensated proliferation of bone marrow and reflect abnormal activation of $\mathrm{T}$ cells.

Differences between overall bone marrow SUV of patients with AA and healthy individuals, patients with AL and patients with MDS were statistically significant; however, bone marrow metabolism of patients with AA has decreased overall. In the clinic, it is occasionally difficult to differentiate AA with atypical manifestations from MDS (5). In the present study, diffuse bone marrow hypermetabolism was not identified using systemic PET/CT of any patient with AA, but was identified in $75 \%$ of patients with MDS. Additionally, patients with MDS presented with more active spleen metabolism compared with patients with AA. These two points may be considered for differential diagnosis of AA and MDS. According to the working mechanism of PET/CT, enhanced spleen metabolism of patients with MDS, as indicated by increased SUV, is ascribed to the marked increased glucose metabolism in tumor cells that are disseminated with blood to the spleen. Whereas in the pathogenesis of AA, inherent defects of hematopoietic stem cells and supportive function defects of hematopoietic microenvironments are independent of the spleen, and immune function disorders primarily originate from abnormal activation of $\mathrm{T}$ cells, $\mathrm{T}$ cells are primarily lymphocytes occurring and maturing in the thymus gland, so spleen SUV of patients with AA are not high.

In regard to the association between systemic PET/CT manifestations and treatment responses of patients with AA, the results of the present study reveal that, in patients with CAA, if neither the $\mathrm{SUV}_{\max }$ in PET/CT nor the T/B cell ratio is high, it potentially indicates poorly compensated bone marrow metabolism and unapparent abnormal activation of $\mathrm{T}$ cells, and the immunosuppressant CsA may not respond well in patients with SAA; if the $\mathrm{SUV}_{\max }$ and the T/B cell ratio have increased, it potentially indicates marked abnormal activation of T cells, and using CsA alone will be insufficient to control immune disorders and more potent immunosuppressants, e.g. antilymphocyte globulin or ATG, have to be administered for an improved response.

For the first time, to the best of our knowledge, the present study has systematically expounded the characteristics of systemic PET/CT manifestations of patients with AA. It is concluded that PET/CT may assist in differential diagnosis of clinically atypical AA and MDS, and the T/B cell ratio may predict treatment efficacy. 


\section{Acknowledgements}

Not applicable.

\section{Funding}

No funding was received.

\section{Availability of data and materials}

All data generated or analyzed during this study are included in this published article.

\section{Authors' contributions}

MC performed the data analyses and wrote the manuscript. LL contributed significantly to data analysis and manuscript preparation, JL contributed to the conception of the study and reviewed the manuscript. BZ performed image examination of patients. JRL, JG, DZ, XT and HW collected and analyzed the patient data.

\section{Ethics approval and consent to participate}

The present study was approved by the ethics committee of the First Affiliated Hospital of Sun Yat-sen University and study participants provided written informed consent.

\section{Patient consent for publication}

Study participants provided their consent for the publication of any data and associated images and all identifying patient data was removed.

\section{Competing interests}

The authors declare that they have no competing interests.

\section{References}

1. Inoue K, Goto R, Okada K, Kinomura S and Fukuda H: A bone marrow F-18 FDG uptake exceeding the liver uptake may indicate bone marrow hyperactivity. Ann Nucl Med 23: 643-649, 2009.

2. Cicone F, Stalder M, Geiger D, Cairoli A, Delaloye AB and Prior JO: Visual and quantitative approach to bone marrow foci of increased glucose uptake on PET/CT in a case of aplastic anaemia. Nuklearmedizin 49: N10-N12, 2010.

3. Harisankar C, Mittal BR, Bhattacharay A and Singh B: FDG-PET/CT in diagnose and early response evaluation of extra-pulmonary tuberculosis in a patient with aplastic anemia. J Postgrad Med 56: 219-221, 2010.

4. Liu Y, Wu H, Huang F, Fan Z and Xu B: Utility of 18F-FDG $\mathrm{PET} / \mathrm{CT}$ in diagnosis and management of mucormycosis. Clin Nucl Med 38: e370-e371, 2013.

5. Marsh JC, Ball SE, Cavenagh J, Darbyshire P, Dokal I, Gordon-Smith EC, Keidan J, Laurie A, Martin A, Mercieca J, et al: Guidelines for the diagnosis and management of aplastic anaemia. Br J Haematol 147: 43-70, 2009.

6. Vardiman JW, Thiele J, Arber DA, Brunning RD, Borowitz MJ, Porwit A, Harris NL, Le Beau MM, Hellström-Lindberg E, Tefferi A and Bloomfield CD: The 2008 revision of the World Health Organization (WHO) classification of myeloid neoplasms and acute leukemia: Rationale and important changes. Blood 114: 937-951, 2009.

7. Valent P, Horny HP, Bennett JM, Fonatsch C, Germing U, Greenberg P, Haferlach T, Haase D, Kolb HJ, Krieger O, et al: Definitions and standards in the diagnosis and treatment of the myelodysplastic syndromes: Consensus statements and report from a working conference. Leuk Res 31: 727-736, 2007.

8. Bakheet SM, Saleem M, Powe J, Al-Amro A, Larsson SG and Mahassin Z: F-18 fluorodeoxyglucose chest uptake in lung inflammation and infection. Clin Nucl Med 25: 273-278, 2000.

9. Goo JM, Im JG, Do KH, Yeo JS, Seo JB, Kim HY and Chung JK: Pulmonary tuberculoma evaluated by means of FDG PET: Findings in 10 cases. Radiology 216: 117-121, 2000.

10. Huang SC: Anatomy of SUV. Standardized uptake value. Nucl Med Biol 27: 643-646, 2000.

11. Krause BJ,Beyer T, Bockisch A, Delbeke D, Kotzerke J, Minkov V, Reiser M and Willich N: FDG-PET/CT in oncology. German guideline. Nuklearmedizin 46: 291-301, 2007 (In German).

12. Stergar H, Bockisch A, Eschmann SM, Krause BJ, Rödel R, Tiling R and Weckesser M: Influence of PET/CT-introduction on PET scanning frequency and indications. Results of a multicenter study. Nuklearmedizin 46: 57-64, 2007.

13. Young NS: Hematopoietic cell destruction by immune mechanisms in acquired aplastic anemia. Semin Hematol 37: 3-14, 2000 